\title{
Pulmonary arteriovenous malformation treated with uniportal video-assisted thoracoscopic lobectomy: a case report
}

\author{
Benedict Dharmaraj $^{1 \wedge}$, Narasimman Sathiamurthy ${ }^{1}$, Nguk Chai Diong $^{1}$, Narendran Balasubbiah $^{1}$, \\ Arvin Rajadurai ${ }^{2}$ \\ ${ }^{1}$ Thoracic Surgery Unit, Department of Surgery, Hospital Kuala Lumpur, Kuala Lumpur, Malaysia; ${ }^{2}$ Interventional Radiology Unit, Department of \\ Radiology, Hospital Kuala Lumpur, Kuala Lumpur, Malaysia \\ Correspondence to: Benedict Dharmaraj. Thoracic Surgery Unit, Department of Surgery, Hospital Kuala Lumpur, Kuala Lumpur, Malaysia. \\ Email: darwin845@yahoo.com.
}

\begin{abstract}
Pulmonary arteriovenous malformations (AVMs) are rare anomalies of the pulmonary vasculature. Sixty percent of patients with pulmonary AVMs' are asymptomatic, while the rest $40 \%$ can present with a myriad of symptoms, the commonest being dyspnea. Although percutaneous embolization has emerged as the gold standard in the treatment of pulmonary AVM, surgery is still indicated in some cases. Video-assisted thoracoscopic surgery (VATS) lung resections has gained popularity and has been proven to have less morbidity, compared to conventional thoracotomy. A 53-year-old male, with a previous history of seizure, was admitted following a motor vehicle accident. He was intubated for respiratory distress. CT thorax was done for evaluation of chest trauma and pulmonary AVM was noted at the lower lobe of the right lung. Post extubation, patient still required high oxygen supplementation. Due to the size of the AVM, he was planned for right lower lobectomy. He underwent transcatheter embolization prior to surgery to minimize blood loss. Thereafter he underwent right uniportal VATS lower lobectomy. Patient was discharged home well on post-operative day 10. No residual AVM was noted on CT angiogram which was done 1 month after surgery. In conclusion, surgery is an option for patients with large pulmonary AVM. Uniportal VATS is an alternative option for surgical resection.
\end{abstract}

Keywords: Case report; pulmonary arteriovenous malformation (pulmonary AVM); uniportal video-assisted thoracoscopic surgery (uniportal VATS); lobectomy

Received: 23 March 2020; Accepted: 04 September 2020; Published: 20 July 2022.

doi: 10.21037 /jovs-20-87

View this article at: http://dx.doi.org/10.21037/jovs-20-87

\section{Introduction}

Pulmonary arteriovenous malformations (AVMs) are rare and described as abnormal communication between the pulmonary arteries and pulmonary veins, bypassing the capillary bed (1). Pulmonary AVMs can be classified as simple or complex, and majority are congenital. Fifty-three percent to $70 \%$ of pulmonary AVMs involve the lower lobe of lungs (1), with $40 \%$ of the patients presenting with neurological complications (2). Although transcatheter embolization is the gold standard treatment for pulmonary
AVM, surgery is indicated in patients who had failed or not suitable for embolization. Video-assisted thoracoscopic surgery (VATS) resection has been proven to be feasible with less morbidity, and uniportal VATS is an alternative surgical approach that can be employed. We present a case of a 63-year-old male with right lower lobe pulmonary AVM, with a history of seizure. He successfully underwent uniportal right video-assisted thoracoscopic surgery (VATS) right lower lobectomy. We present the following article in accordance with the CARE reporting checklist (available at

^ ORCID: 0000-0002-6767-8022. 


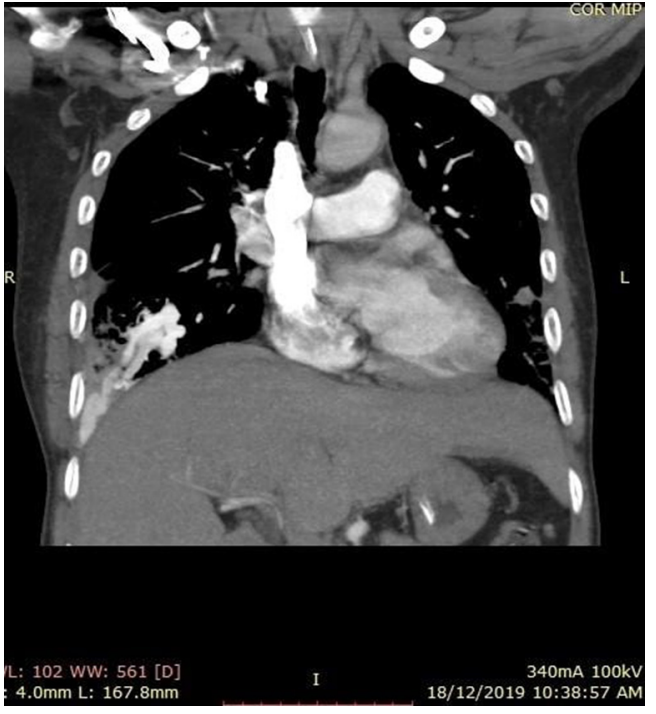

Figure 1 Coronal view of computed tomography thorax of patient showing left lower lobe AVM. AVM, arteriovenous malformation.

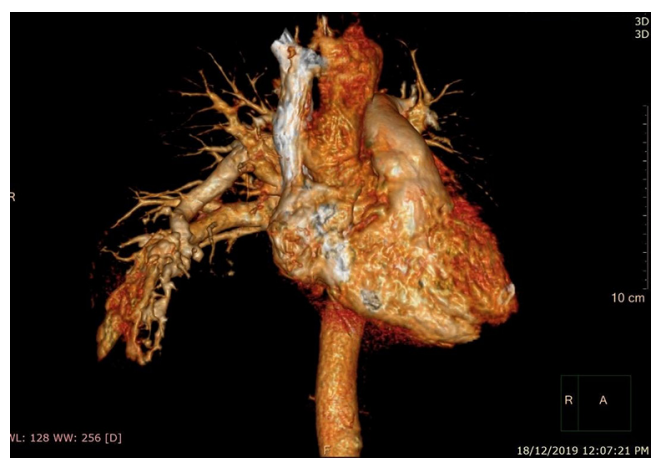

Figure 2 Three-dimensional reconstruction of computed tomography image showing left lower lobe AVM. AVM, arteriovenous malformation.

https://jovs.amegroups.com/article/view/10.21037/jovs-20$87 /$ rc).

\section{Case presentation}

A 53-year-old male, with a background history of seizure, was admitted to a tertiary hospital following a motor vehicle accident. He sustained bilateral ribs fracture; tear drop fracture of C3 and C4 anterior vertebral body (treated conservatively with soft collar) and subarachnoid hemorrhage at parasagittal region (also treated conservatively).

He was intubated upon admission due to respiratory distress and required ICU stay for 16 days. A CT thorax was done on post trauma day 3, which revealed abnormally dilated prominent vessels at right lower lobe (communication between right pulmonary artery and inferior pulmonary vein) (Figures 1,2 ). He was extubated to $60 \%$ high flow mask, yet his oxygen saturation remained between $88-92 \%$.

Past medical history revealed that the patient had presented in 2014 for multiple episodes of epilepsy. Thorough investigation revealed that he had myogenic brain abscess as well a right pulmonary AVM, for which he was asymptomatic. Patient then defaulted follow-up.

Patient was then transferred to a thoracic surgery unit and was planned for a right lower lobectomy. Pre-operative investigations were unremarkable.

He underwent angiogram prior to surgery. There was abnormal nidus of vessels, which were supplied by two branches from pulmonary artery to lower lobe. Another communication was noted from right lateral thoracic artery. Coiling was done.

Patient underwent uniportal right VATS lower lobectomy immediately after the angioembolization procedure (Figure 3). Intraoperatively, the entire lung was adhered densely to the chest wall. Multiple feeder vessels were seen arising from the chest wall. The interlobar pulmonary artery and the inferior pulmonary vein was abnormally dilated (Figure 4). Total blood loss was $1 \mathrm{~L}$ and surgery was entirely thoracoscopic (Video 1).

He was extubated 7 hours after surgery and was weaned to room air on post-operative day 2. He was discharged home well on post-operative day 10. CT angiogram was done 1 month after surgery, and no residual or new AVM was noted. Figure 5 depicts timeline of management of for the patient.

All procedures performed in this study were in accordance with the ethical standards of the institutional and national research committee and with the Helsinki Declaration (as revised in 2013). Written informed consent was obtained from the patient for publication of this study and any accompanying images. A copy of the written consent is available for review by the editorial office of this journal.

\section{Discussion}

Pulmonary AVM was first described by Churton in 1897 in a 12-year-old boy who presented with episodes of epistaxis, hemoptysis and a loud pulmonary systolic bruit. Postmortem examination on this patient revealed bilateral 


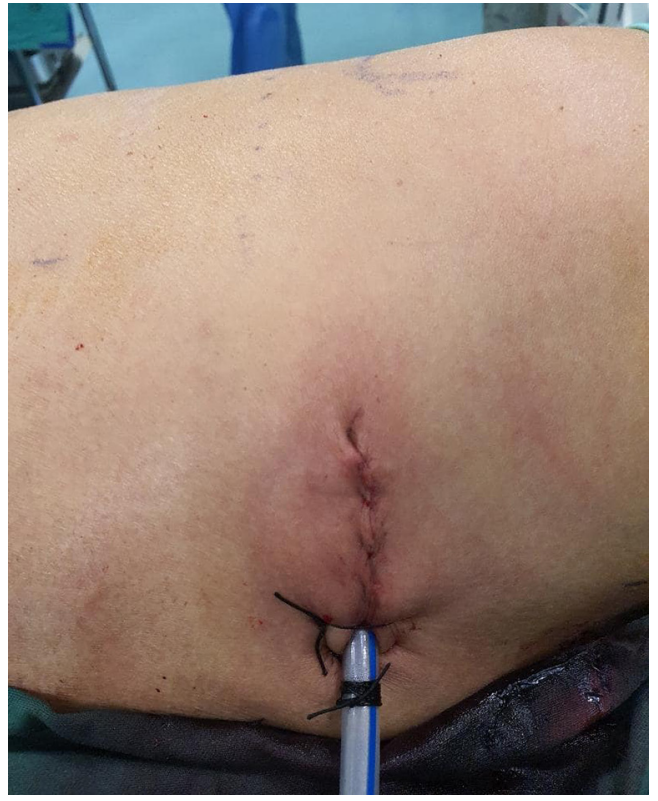

Figure 3 Surgical scar of patient (uniportal scar) with chest tube insertion after surgery.

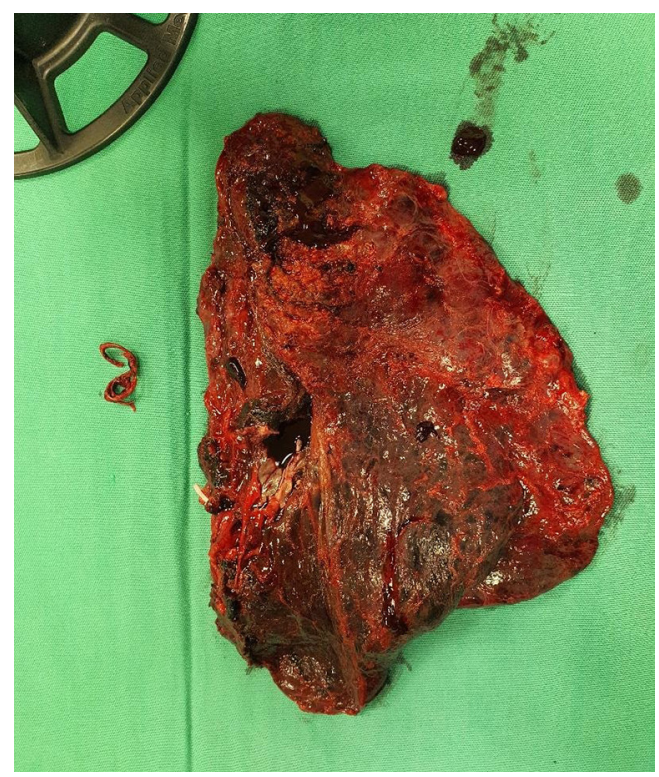

Figure 4 Resected lower lobe, along with embolization coil (seen on the right of the specimen).

multiple pulmonary AVMs $(1,3)$. Since then, various names have been used in literature to describe this entity, namely pulmonary arteriovenous aneurysm, hemangioma of lung and pulmonary telangiectases.

Pulmonary AVMs are rare, and the incidence is reported

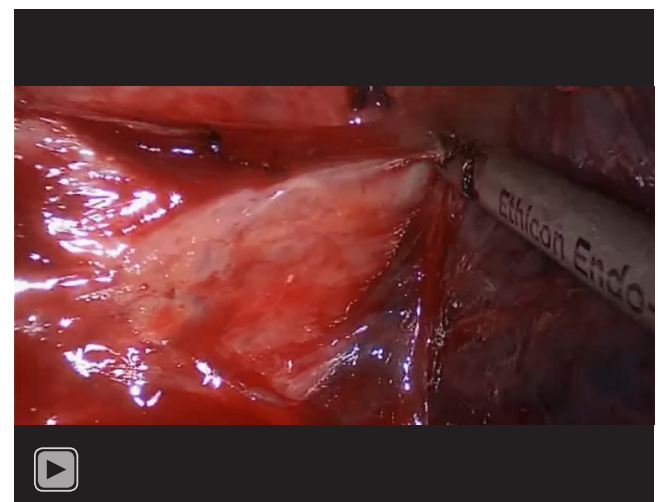

Video 1 Uniportal VATS lobectomy for pulmonary AVM. VATS, video-assisted thoracoscopic surgery; AVM, arteriovenous malformation.

between $2-3$ per 100,000 population (3). An autopsy study that was conducted in Johns Hopkins in 1953, revealed only three cases of pulmonary AVM in 15,000 autopsies performed (4). The Mayo Clinic reported about 194 cases in 45 years, indicating an annual incidence of 4.3 cases per year (5). It is more common in females, with a male to female ratio of $1: 1.5-1.8(3,6)$.

The exact pathogenesis of pulmonary AVM is still unknown. Pulmonary AVMs can be further divided into simple and complex. Simple pulmonary AVMs constitute $80 \%$ of all pulmonary AVMs and are defined as single feeding segmental artery to a single draining vein. Complex pulmonary AVMs constitutes the remaining $20 \%$ of cases and are defined as two or more feeding arteries to multiple draining veins (1,5-7). Anabawi et al. had further classified pulmonary AVM as follow:

(I) Grade 1: multiple small AV fistula without aneurysm;

(II) Grade 2: large peripheral AV aneurysm;

(III) Grade 3A: large central aneurysm;

(IV) Grade 3B: large AV aneurysm with anomalous venous drainage;

(V) Grade 3C: multiple small AV fistula with anomalous venous drainage;

(VI) Grade 4A: large venous aneurysm with systemic artery communication;

(VII) Grade 4B: large venous aneurysm without fistula;

(VIII) Grade 5: anomalous venous drainage with fistula.

Based on the classification, the patient in this case report had a Grade 2 pulmonary AVM.

Eighty percent of pulmonary AVMs are congenital, and 


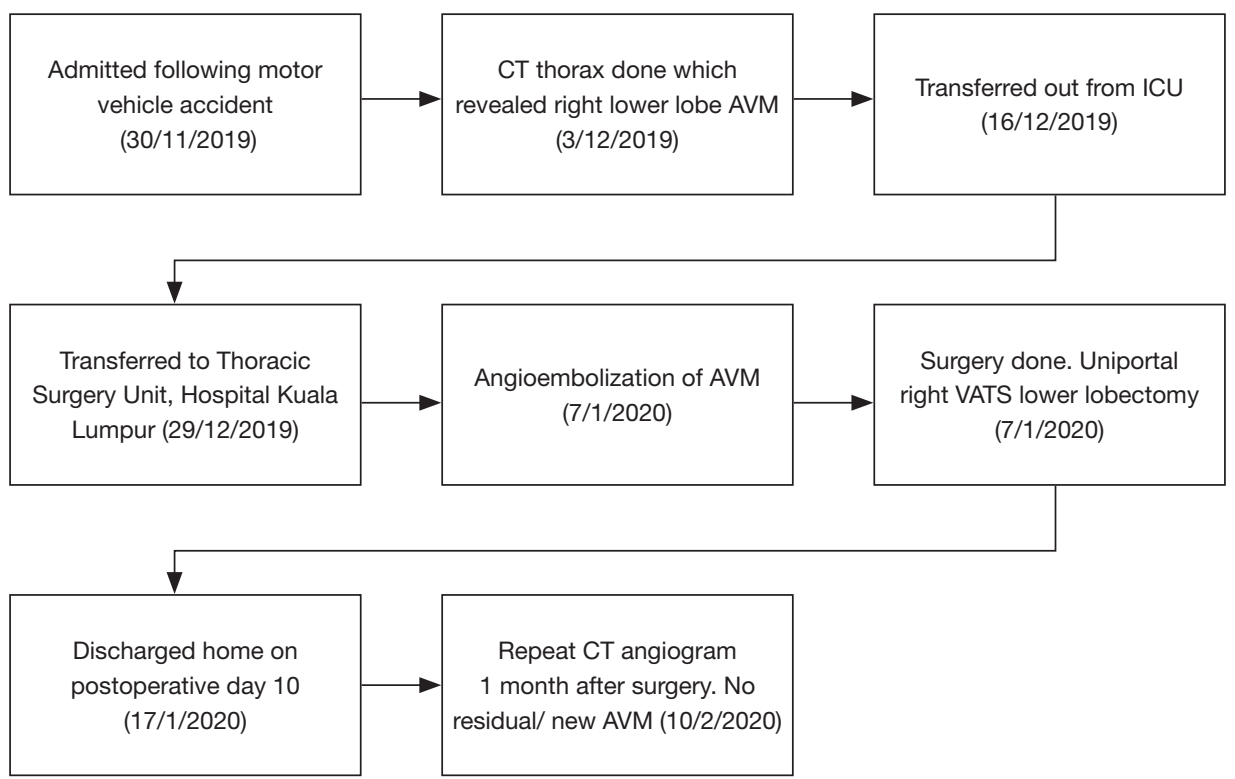

Figure 5 Timeline of historical and current information. AVM, arteriovenous malformation. VATS, video-assisted thoracoscopic surgery.

of these cases, $47-80 \%$ AVM have been associated with Osler-Weber-Rendu syndrome or hereditary hemorrhagic telangiectasia (HHT). Conversely, $5-15 \%$ of patients with HHT have been noted to have pulmonary AVM (3). Secondary pulmonary AVM are rarer, and causes include chest trauma, thoracic surgery, infection (schistosomiasis, actinomycosis) and mitral stenosis. Patients can have single (42-74\%) and multiple (35-65\%) pulmonary AVM; multiple AVMs are more commonly seen in patients with HHT (5).

Ten percent of pulmonary AVM are detected in childhood, and majority of cases are detected within the first 3 decades of life. Sixty percent of patients with pulmonary AVM are asymptomatic $(3,6)$. Common presentation among the symptomatic patients include dyspnea, hypoxemia with high incidence of orthodexia (desaturation while being in upright position), chest pain and myocardial infarction.

Central nervous system (CNS) complications remains the most common complication of pulmonary AVM and has been reported to be as high as $40 \%$ among patients (2). Presentation include migraine (43\%), transient ischemic attack $(37 \%)$, cerebrovascular accident $(8 \%)$, cerebral abscess (6-9\%) and seizure (8\%) (3). The patient in our case report presented with seizure and had cerebral abscess.

Chest radiographs can be an important diagnostic tool in diagnosis and follow up in patients with pulmonary AVM. However, one study shows that a normal chest radiograph can be seen in about $10-40 \%$ of patients with pulmonary AVM (8). Contrast enhanced CT is a valuable tool in the diagnosis of pulmonary AVM. It aids in defining the vascular anatomy of the AVM. Currently, transthoracic contrast echocardiography (TTCE) is considered the gold standard in diagnosis of pulmonary AVM (7). It is comparable to contrast enhanced CT in calculating the size of the shunt. It is more a reliable tool in establishing the grade of the shunting, thus aiding the decision of treatment. Magnetic resonance angiography can also be used as a diagnostic tool. However, it is not as specific and sensitive as a contrast enhanced CT and is also more expensive.

Treatment modalities for pulmonary AVM has evolved over the decades. Traditionally, treatment was administered to symptomatic patients, asymptomatic patients with AVMs of more than $3 \mathrm{~mm}$, patients with progressive enlargement of AVM, and for patients with paradoxic embolization $(1,5,6)$. In untreated patients, morbidity rate was recorded to be $50 \%$ and mortality rate was $11 \%(3,5)$. Treatment modalities include embolization, surgery and hormonal treatment.

Surgery has been the mainstay of treatment for pulmonary AVM before 1978. The $1^{\text {st }}$ successful surgery was recorded in 1942, where Hepburn and Dauphinee reported the disappearance of patient's polycythemia and digital clubbing following pneumonectomy for pulmonary 
hemangioma. In 1945, Packard and Waring reported the successful treatment of a 31-year-old male with ligation of pulmonary artery (3). Surgical options for pulmonary AVM include ligation, local excision, segmentectomy, lobectomy and pneumonectomy. Lung transplant is considered for patients with diffuse bilateral disease, but this endeavor is rarely undertaken.

In 1978, Taylor reported the $1^{\text {st }}$ successful percutaneous embolization for pulmonary AVM, revolutionizing the treatment for pulmonary AVM $(3,8)$. Since then, percutaneous transcatheter embolization has taken over as the treatment of choice for pulmonary AVM. Success rate of treatment via embolization was reported as high as $83 \%$ (6). Complications and morbidity rates have been reported to be lower than surgical intervention. Complications following embolization include device migration, air embolism, lung infarction, revascularization, and transient pleurisy. One study reports revascularization rate of $25 \%$ (8) hence patients are required to undergo 6-12 monthly CT imaging to detect reperfusion. Limitations of percutaneous embolization include inability to treat AVMs of less than $2 \mathrm{~mm}$ with the current technique. Patients with HHT may have multiple pulmonary AVMs, with only a proportion of these AVMs amenable for embolization.

Surgery is also indicated in patients who had failed embolization, intrapleural rupture and for large centrally located lesions $(1,3)$. Some surgeons prefer surgery to embolization due to the risk of revascularization and recanalization following embolization (9). Not many papers report of surgical management of pulmonary AVM, as embolization is the more popular choice of treatment. However, the rate of mortality following pulmonary resection is low, reported as zero in 1960 (7). With the advent of thoracoscopic surgery, the morbidity and mortality rate has dropped further. Ishikawa et al. reported a series of 5 patients with pulmonary AVM treated with thoracoscopic lung resection. In their series, the median post-operative stay was 2 days, and no major complications were noted (10). Bakhos et al. (11) reported on two patients with pulmonary AVM, who underwent VATS resection. Both of their patients had failed multiple embolization. Surgery was done with less morbidity and both patients were symptoms free at 9 months post-surgery. Reichert et al. (9) and Akiyama et al. (12) also reported excellent outcomes in their patients', who underwent VATS resection for pulmonary AVM. VATS pulmonary resection has been proven to be more tolerable and has lesser morbidity, compared to thoracotomy.
Although the first choice of treatment for pulmonary AVM is embolization, surgical resection by uniportal VATS can be considered in experienced hands. This method could be limited by steep learning curve with rare incidence with rare incidence of pulmonary AVM requiring surgery, which naturally carries high risk of bleeding. This case report could be among the very few cases in the literature having pulmonary AVM resected by uniportal VATS method.

\section{Conclusions}

In conclusion, small pulmonary AVM should be treated by angioembolization. In experienced hands, large AVM can be resected surgically. Uniportal VATS is an alternative option in performing the resection and has a low morbidity rate. Preoperative embolization of the AVM can reduce surgical blood loss.

\section{Acknowledgments}

Funding: None.

\section{Footnote}

Reporting Checklist: The authors have completed the CARE reporting checklist. Available at https://jovs.amegroups. com/article/view/10.21037/jovs-20-87/rc

Conflicts of Interest: All authors have completed the ICMJE uniform disclosure form (available at https://jovs. amegroups.com/article/view/10.21037/jovs-20-87/coif). The authors have no conflicts of interest to declare.

Ethical Statement: The authors are accountable for all aspects of the work in ensuring that questions related to the accuracy or integrity of any part of the work are appropriately investigated and resolved. All procedures performed in this study were in accordance with the ethical standards of the institutional and national research committee and with the Helsinki Declaration (as revised in 2013). Written informed consent was obtained from the patient for publication of this study and any accompanying images. A copy of the written consent is available for review by the editorial office of this journal.

Open Access Statement: This is an Open Access article distributed in accordance with the Creative Commons 
Attribution-NonCommercial-NoDerivs 4.0 International License (CC BY-NC-ND 4.0), which permits the noncommercial replication and distribution of the article with the strict proviso that no changes or edits are made and the original work is properly cited (including links to both the formal publication through the relevant DOI and the license). See: https://creativecommons.org/ licenses/by-nc-nd/4.0/.

\section{References}

1. Georghiou GP, Berman M, Vidne BA, et al. Pulmonary arteriovenous malformation treated by lobectomy. Eur J Cardiothorac Surg 2003;24:328-30.

2. Karavdik K, Pilav I, Guska S, et al. Symptomatic pulmonary arteriovenous malformations in a 10-year-old boy-a case report. Medical Case Reports 2018;4:65.

3. Khurshid I, Downie GH. Pulmonary arteriovenous malformation. Postgrad Med J 2002;78:191-7.

4. Mangla A, Nevares A, Yamani N, et al. Pulmonary arteriovenous malformation: a rare cause of dyspnoea on exertion. BMJ Case Rep 2014;2014:bcr2014204087.

5. Navratil M, Vidjak V, Rubić F, et al. Pulmonary arteriovenous malformations presenting as difficult-tocontrol asthma: a case report. J Med Case Rep 2013;7:32.

6. Sharma P, Kochar P, Sharma S, et al. A case of pulmonary

doi: $10.21037 /$ jovs-20-87

Cite this article as: Dharmaraj B, Sathiamurthy N, Diong NC, Balasubbiah N, Rajadurai A. Pulmonary arteriovenous malformation treated with uniportal video-assisted thoracoscopic lobectomy: a case report. J Vis Surg 2022;8:30. arteriovenous malformation: role of interventional radiology in diagnosis and treatment. Ann Transl Med. 2017;5:345.

7. Sladden D, Casha A, Azzopardi C, et al. A large pulmonary arteriovenous malformation causing cerebrovascular accidents. BMJ Case Rep 2015;2015:bcr2014207786.

8. Tellapuri S, Park HS, Kalva SP. Pulmonary arteriovenous malformations. Int J Cardiovasc Imaging 2019;35:1421-8.

9. Reichert M, Kerber S, Alkoudmani I, et al. Management of a solitary pulmonary arteriovenous malformation by video-assisted thoracoscopic surgery and anatomic lingula resection: video and review. Surg Endosc 2016;30:1667-9.

10. Ishikawa Y, Yamanaka K, Nishii T, et al. Video-assisted thoracoscopic surgery for pulmonary arteriovenous malformations: report of five cases. Gen Thorac Cardiovasc Surg 2008;56:187-90.

11. Bakhos CT, Wang SC, Rosen JM. Contemporary role of minimally invasive thoracic surgery in the management of pulmonary arteriovenous malformations: report of two cases and review of the literature. J Thorac Dis 2016;8:195-7.

12. Akiyama S, Hanada S, Uruga H, et al. Hereditary hemorrhagic telangiectasia with pulmonary arteriovenous malformations and embolic strokes treated successfully with video-assisted thoracoscopic resection. Intern Med 2013;52:1091-4. 